\title{
INOVASI SLURRY ICE MACHINE INDONESIA/MESIN PEMBUAT BUBUR ES (MPBE) MERAH PUTIH METODE SCRAPED-SURFACE BERKAPASITAS 1,5 DAN 0,5 TON/HARI
}

\author{
Nur Mahmudi Ismail ${ }^{\star 1}$, Eko Fajar Nurprasetyo², Ahmad Syihan Ismail², Esha Ganesha², \\ Riyo Srisantoso Wardoyo ${ }^{2}$, Andri Bayupati ${ }^{2}$, Ibnu Susakti ${ }^{2}$, Mahyudi ${ }^{2}$ \\ 1Badan Pengkajian dan Penerapan Teknologi, Jalan M.H Thamrin no 8 \\ ${ }^{2} \mathrm{PT}$ Hikari Solusino Sukses
}

Diterima: 30 Mei 2021/Disetujui: 31 Agustus 2021

Korespondensi: nurmahmudiismail@gmail.com

Cara sitasi: Ismail NM, Nurprasetyo EF, Ismail AS, Ganesha E, Wardoyo RS, Bayupati A, Susakti I, Mahyudi. 2021. Inovasi slurry ice machine Indonesia/mesin pembuat bubur es (MPBE) merah putih metode scrapedsurface berkapasitas 1,5 dan 0,5 ton/hari. Jurnal Pengolahan Hasil Perikanan Indonesia. 24(2): 249-254.

\begin{abstract}
ABSTRAK
Rekayasa terhadap evaporator, kondensor, dan sistem kontrol elektronik telah dilakukan untuk menghasilkan inovasi sebuah unit slurry ice machine/mesin pembuat bubur es (MPBE) yang dioperasikan dengan tenaga listrik 3 phase. Penelitian ini bertujuan untuk menghasilkan mesin pembuatan bubur es yang ramah lingkungan. Metode pembuatan dilakukan dengan menggunakan desain yang dibuat oleh PT Hikari Solusino Sukses dengan kapasitas masing-masing 0,5 dan 1,5 ton/hari . Hasil menunjukkan bahwa MPBE dapat mulai memproduksi bubur es sekitar 2 menit dengan kapasitas produksi $1.500 \mathrm{~kg}$ bubur es dalam 24 jam. Untuk memenuhi kebutuhan konsumen telah diproduksi unit MPBE berkapasitas $1.500 \mathrm{~kg} / 24 \mathrm{jam}$ yang dioperasikan dengan motor berbahan bakar solar dan berkapasitas $500 \mathrm{~kg} / 24$ jam yang dioperasikan dengan motor berbahan bakar bensin. Dibandingkan dengan unit prototipe MPBE yang telah dibuat dan unit yang dijual di pasar internasional, inovasi unit MPBE ini dapat memproduksi bubur es lebih cepat, yaitu 2 menit berbanding 20-30 menit, serta fraksi bubur es yang tinggi, hingga 90\% dibandingkan 30-40\%. Berdasarkan nilai lebih pada kualitas bubur es yang diproduksi, variasi pengoperasian menggunakan motor penggerak berbahan bakar bensin dan solar, serta dukungan ekosistem manufaktur di Indonesia, inovasi MPBE ini diyakini dapat diproduksi secara komersial karena harga dan kualitasnya yang kompetitif.
\end{abstract}

Kata kunci: bensin, listrik, inovasi, MPBE Merah Putih, solar

\section{Innovation of Indonesian Scraped-Surface Slurry Ice Machine with 1.5 and 0.5 Ton Per Day Capacity}

\begin{abstract}
Designing evaporator, condensor and electronic control were conducted to produce an innovation of slurry ice machine operated by 3-phase electricity. Result indicated that the machine start producing slurry ice within about 2 minutes, with capacity of $1,500 \mathrm{~kg} / 24$ hours and slurry ice crystal fraction about $90 \%$. Based on consumer request, two slurry ice machine has ben made. The first one was a 1,500 kg/24 hours operated by diesel engine, while the second was a $500 \mathrm{~kg} / 24$ hours slurry ice machine operated by gasoline engine. Compared to the prototype unit and machine available in the commercial market, the innovation unit start producing slurry ice much faster, 2 minutes vs 20-30 minutes, and produce fraction of slurry ice crystal much higher, $90 \%$ vs $30-40 \%$. Due to its superior quality, the practical mode of operation both by diesel oil and gasoline, and supported by ecosystem manufacture available in Indonesia, it is prospective to produce the slurry ice machine commercially.
\end{abstract}

Keywords: diesel, electricity, gasoline, Indonesia slurry ice machine, innovation 


\section{PENDAHULUAN}

Penanganan ikan segar merupakan bagian penting dari rantai pasokan industri perikanan. Starling dan Diver (2005) melaporkan bahwa faktor-faktor yang memengaruhi mutu ikan terdiri dari faktor biologis (umur, spesies, tingkat kematangan seksual dan adanya penyakit) dan faktor non biologis (teknik penangkapan, penanganan, pendinginan, dan penyimpanan). Jika teknik penanganan ikan yang dilakukan baik, maka ikan akan memiliki kualitas yang baik dan harga jual yang tinggi.

Teknologi slury ice/bubur es yang digunakan untuk mendinginkan dan mengawetkan produk perikanan pada tahun 1980 ditelaah secara mendalam dan terstruktur di Kanada, Eropa, dan Asia. Teknologi ini tidak hanya sebagai pendingin namun juga pengawet perikanan yang sempurna. Teknologi slurryice terdapat di dalam panduan serta peraturan resmi pengawetan ikan. Teknologi ini dapat menyimpan kalor dengan baik, mendinginkan secara merata dan cepat ke seluruh permukaan tubuh ikan sehingga menghasilkan ikan berkualitas baik yang tahan lama. Kelebihan lainnya adalah struktur bubur es bentuknya bulat dan halus sehingga permukaan/kulit ikan tidak gampang rusak dan mempertahankan nilai ekonomi ikan tetap tinggi. Pada tahun 2010, 700 industri perikanan di dunia telah menggunakan teknologi tersebut, dengan persebaran utama di Islandia, Jepang dan Norwegia (Kauffeld et al. 2010). Sebagai negara tropis, Indonesia menghadapi risiko kerusakan ikan yang tinggi, sehingga perlu diperlukan penguasaan teknologi slurry ice dalam industri perikanan. Saat ini, nelayan/pelaku usaha perikanan Indonesia belum menggunakan teknologi slurry ice. Hal tersebut terjadi karena meski unggul, namun nelayan dan pelaku usaha tidak familiar dengan teknologi tersebut serta harga mesin mahal. Selain itu, mesin slurry ice yang tersedia secara komersial di pasar internasional tidak kompatibel dengan laut tropis. Indonesia perlu menguasai teknologi slurry Ice dan memiliki inovasi slurry ice machine/mesin pembuat bubur es (MPBE) yang berkualitas dan kompetitif harganya untuk menghindari food loss and waste komoditas ikan sebesar 4,89 juta ton ikan dengan nilai setara Rp81,17 triliun. Oleh karena itu keberadaan mesin ini sangat dibutuhkan dalam rangka menghindari food loss pada ikan. Penelitian ini bertujuan untuk menghasilkan mesin pembuatan bubur es dalam penanganan ikan kapasitas 0,5 dan 1,5 ton/hari.

\section{BAHAN DAN METODE Bahan dan Alat}

Bahan yang digunakan adalah air dan ikan untuk percobaan pengujian. Alat yang digunakan adalah mesin pembuat bubur es (MPBE) yang dibuat oleh PT Hikari Solusino Sukses.

\section{Metode Peneltian}

Proses inovasi didasarkan pada hasil kajian terhadap output rekayasa ulang dan pembuatan prototipe slurry ice machinel mesin pembuat bubur es (MPBE) yang telah dilakukan sebelumnya. Hasil pembuatan prototipe MPBE menunjukkan bahwa mesin mampu mengolah air tambak in situ, air laut dan air laut tiruan menjadi bubur es dan efektif digunakan untuk mendinginkan dan mengawetkan kesegaran udang budi daya tambak dan ikan. Meski prototipe MPBE sudah sukses memproduksi bubur es dari air bergaram dan efektif sebagai media pengawet ikan, namun masih memiliki beberapa kelemahan mendasar pada kualitas mesinnya. Kelemahan tersebut antara lain waktu awal terbentuknya kristal bubur es masih lama (20menit), fraksi kristal bubur es yang terbentuk cukup rendah (30-40\%), dan kapasitas produksi baru $700 \mathrm{~kg} / 24$ jam. Ekosistem dan daya dukung manufaktur Indonesia lebih rendah daripada negara produsen MPBE misalnya Jepang dan Cina. MPBE yang akan dibuat di Indonesia diprediksi tidak akan kompetitif dari sisi harga, di samping kualitas keluarannya baru pada tahap sama, belum lebih unggul dari slurry ice machine contoh yang diperoleh dari pasar komersial internasional.

Faktor penting yang perlu diperhatikan dalam inovasi suatu produk adalah manufacturability, ekosistem yang memungkinkan suatu produk diproduksi 
secara massal, konsisten kualitasnya dan produk dapat diterima oleh konsumen secara teknis dan ekonomis. Berdasarkan beberapa kekurangan terhadap kualitas prototipe MPBE yang telah dihasilkan, peneliti melepaskan desain prototipe MPBE yang didasarkan pada ekosistem daya dukung manufaktur negara maju dan beriklim subtropis. Selanjutnya, dilakukan adaptasi dengan ekosistem daya dukung manufaktur Indonesia yang beriklim tropis. Inovasi slurry ice machine/ MPBE jenis baru, direkayasa untuk memproduksi bubur es lebih cepat, lebih berkualitas, mudah dioperasikan, dapat diproduksi secara massal dan lebih terjangkau harganya. Lebih penting lagi, karena masih banyak wilayah perikanan Indonesia berada di daerah terpencil, tenaga listrik yang kurang memadai bahkan ada yang tidak tersedia tenaga listrik, maka inovasi slurry ice machine harus dapat dioperasikan dengan motor berbahan bakar solar, bensin, atau gas.

Slurry ice machine yang dioperasikan dengan tenaga listrik terdiri dari empat komponen utama, yaitu kompresor, kondensor, evaporator dan kontrol. Sementara untuk daerah terpencil dan tidak tersedia tenaga listrik, diperlukan satu tambahan komponen utama kelima, yaitu motor penggerak. Untuk mencapai produk dengan kualitas dan harga yang kompetitif, inovasi slurry ice machine difokuskan pada rekayasa evaporator, kondensor dan kontrol. Selain itu dilakukan modifikasi agar unit slurry ice machine dapat dioperasikan dengan motor penggerak berbahan bakar solar, bensin, atau gas. Sementara kompresor dan motor penggerak diperoleh dari pasar komersial.

\section{HASIL DAN PEMBAHASAN}

Unitslurryice machine/MPBE baru (Figure 1) yang dioperasikan dengan tenaga listrik 3 phase berhasil dibuat dan berbeda dengan prototipenya karena evaporator, kondensor, dan sistem kontrol elektroniknya direkayasa dari prototipenya. Hasil menunjukkan, bahwa MPBE dapat mulai memproduksi bubur es sekitar 2 menit dengan kapasitas produksi $1.500 \mathrm{~kg}$ bubur es dalam 24 jam. Fraksi kristal bubur es yang diproduksi dapat melebihi $90 \%$. Apabila dibandingkan dengan unit prototipe MPBE yang telah dibuat dan unit slurry ice machine yang dijual di pasar internasional, inovasi unit ini dapat menghasilkan bubur es lebih cepat, 2 menit dibandingkan 20-30 menit, serta fraksi bubur es yang lebih tinggi, 90\% dibandingkan 30-40\%, dengan kapasitas produksi lebih besar, 1.500 vs $700 \mathrm{~kg} / 24$ jam. Berdasarkan kualitas bubur es yang dihasilkan serta dukungan manufaktur di Indonesia, inovasi slurry ice machine/MPBE baru yang diberi nama slurry ice machine Indonesia/ MPBE Merah Putih berpeluang untuk diproduksi secara komersial. Mesin ini juga bermanfaat dalam penanganan ikan untuk menjaga ikan tetap segar. Menurut Munandar et al. (2009) penilaian organoleptik merupakan rata-rata nilai karakteristik untuk menentukan tingkat kesegaran ikan yang meliputi kenampakan mata, warna insang, bau, dan tekstur. Ikan yang telah busuk, memiliki mata cekung serta lebih keruh, warna insang
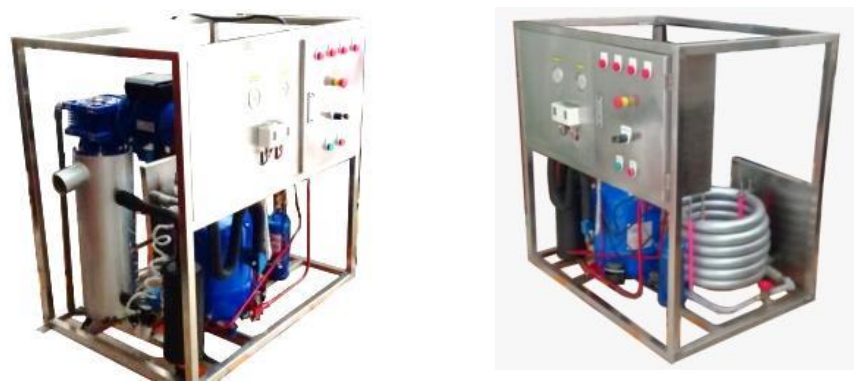

Figure 1 Innovation of evaporator (left) and condensor (right) of slurry ice machine Indonesia using scraped-surface method with 1,500 kg /24 hour capacity. Operated with 3 phase electricity, gasoline, or diesel oil. 
merah kusam dan berlendir, bau amoniak dan asam, tekstur lunak dan kurang elastis. Metusalach et al. (2014) menjelaskan bahwa terdapat beberapa faktor yang memengaruhi terjadinya penurunan mutu dan kerusakan ikan setelah ikan ditangkap antara lain kurang memadainya fasilitas, proses penanganan ikan yang belum sesuai prosedur, dan proses penangkapan ikan. Selain itu mutu ikan sangat dipengaruhi oleh proses penangkapan yang berhubungan langsung dengan cara ikan mati.

Kauffeld (2019) menjelaskan bahwa teknologi slurry ice pertama kali dipatenkan pada awal 1930, selanjutnya dikembangkan dalam bentuk aliran bubur es sebagai pendingin pada 1966, dan baru pada tahun 1985 benar-benar dibangun dan diteliti sistem bubur es. Dalam perkembangannya, Liu et al. (2019) menjelaskan di antara 5 metode produksi bubur es, metoda scrapedsurface paling berkembang secara teknologi dan paling banyak digunakan oleh masyarakat. Desain metode scraped-surface ini berbentuk modular sehingga memudahkan secara teknik bagi pengguna jika di kemudian hari berencana untuk mengembangkan kapasitas produksi slurry ice. Keunggulan lain pada teknologi slurry ice adalah mengolah langsung air bergaram yang bisa diambil dari laut atau tambak. Hal ini membuat mesin slurry ice memungkinkan dioperasikan di berbagai daerah terpencil yang sulit suplai air tawar, bahkan dapat dioperasikan di atas perahu atau kapal penangkap ikan dengan mengambil bahan baku es berupa air langsung dari laut. Nelayan tidak perlu menyediakan ruang atau wadah khusus untuk menampung cadangan air tawar.

Melihat data masih banyak perahu yang belum dapat menerapkan rantai dingin, dan masih banyak wilayah perikanan belum tersedia es dengan jumlah yang cukup dan terjangkau, selanjutnya dilakukan sosialisasi keunggulan hasil inovasi unit slurry ice machine Indonesia secara bertahap baik langsung kepada nelayan, koperasi nelayan, pelaku usaha perikanan tangkap/budi daya, masyarakat pengolah hasil perikanan, serta instansi pemerintah daerah dan pemerintah pusat (Figure 2).

Tahun 2019 KEMENRISTEKDIKTI memesan MPBE Merah Putih berkapasitas

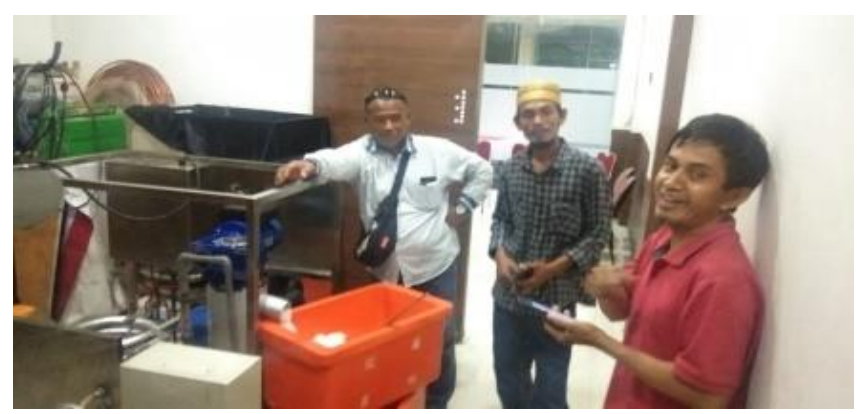

Figure 2 Head of fisheries office district of Sapekeri fisherman (right) visiting slurry ice machine Indonesia showroom at PT Hikari Solusindo Sukses

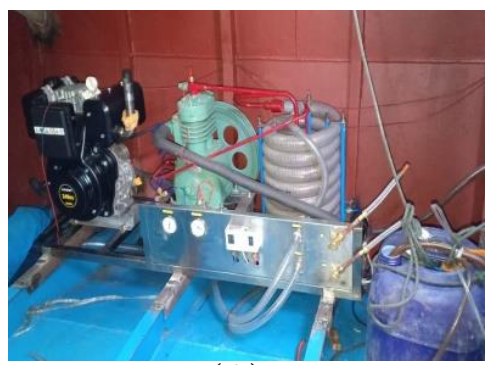

(A)

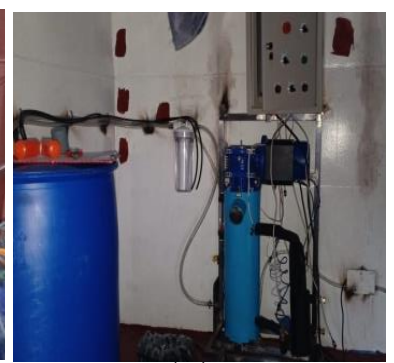

(B)

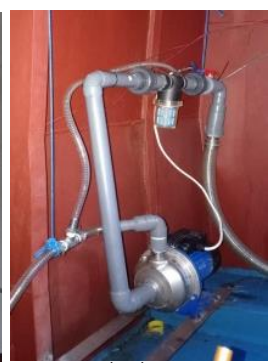

(C)

Figure 3 (A) Hot unit; (B) Cold unit; (C) Water system of slurry ice machine Indonesia operated with diesel oil on flat plate ship from KEMENRISTEKDIKTI RI at Politeknik Negeri Tual 
$1.500 \mathrm{~kg} / 24$ jam yang dioperasikan dengan motor penggerak berbahan bakar solar untuk dipasang pada kapal pelat datar (Figure 3). Sebelum diperbantukan kepada Politeknik Negeri Tual, dilakukan uji kelaikan operasi MPBE Merah Putih untuk mengolah air laut menjadi bubur es in situ di Tual. Selanjutnya bubur es digunakan untuk mendinginkan dan mengawetkan lobster segar yang ditangkap oleh ABK kapal pelat datar (Figure 4). MPBE Merah Putih berkapasitas $1.500 \mathrm{~kg} / 24$ jam dapat dioperasikan dengan motor berbahan bakar solar untuk mengolah air laut menjadi bubur es sebagai pendinginn dan pengawet produk perikanan Indonesia.

Dibandingkan dengan slurry ice machine komersial, MPBE Merah Putih lebih unggul kualitas keluarannya, kompetitif harganya, dan selain dioperasikan menggunakan listrik, alat juga dapat beroperasi menggunakan solar, bensin, maupun gas (Figure 5). Keunggulan inovasi ini memungkinkan MPBE Merah Putih dapat dioperasikan untuk melakukan revolusi rantai dingin industri perikanan Indonesia.
Tahapannya dapat dilakukan sebagai berikut, pertama bagi perahu bermotor yang belum punya sistem pendingin yang terkontrol tetapi ada genset cukup besar, dapat menggunakan MPBE Merah Putih yang dioperasikan dengan tenaga listrik.

\section{KESIMPULAN}

Inovasi unit slurry ice machine Indonesia/ MPBE Merah Putih merupakan karya monumental Indonesia di bidang perikanan. Melalui inovasi ini, diharapkan terbangun ekosistem kolaborasi antara pemerintah, pemerintah daerah dan BUMN/BUMD dalam mendukung revolusi industri perikanan di seluruh Indonesia melalui kecukupan produksi bubur es dengan harga terjangkau oleh nelayan dan pelaku usahan perikanan lainnya.

\section{DAFTAR PUSTAKA}

Agustini TW, Nur M, Kusdiyantini E. 2017. Application of ozone-slurry ice combined system for maintaining the freshness of

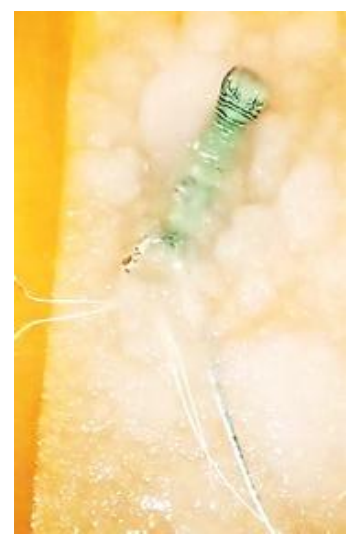

Figure 4 Slurry ice to keep the freshness of tropical rock lobster catched at Tual waters

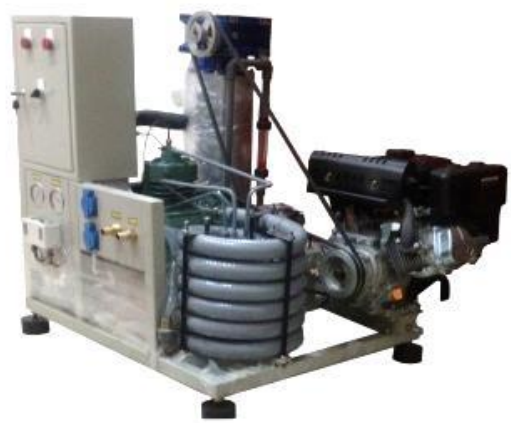

Figure 5 Innovation of slurry ice machine Indonesia using scraped-surface method with $500 \mathrm{~kg} / 24$ hours capacity operated with gasoline. 
red tilapia and short-bodied mackerel during cold storage. Jurnal Pengolahan Hasil Perikanan Indonesia. 20(2): 424431.

Akande G, Diei-Ouadi Y. 2010. Post-Harvest Losses in Small-scale Fisheries-Case Studies in Five sub-Saharan African Countries. Rome: FAO Fisheries and Aquaculture Tech.

[BSN] Badan Standardisasi Nasional. 2006. Uji Organoleptik Ikan Segar. SNI 01-23462006. Jakarta (ID): Badan Standardisasi Nasional.

Kauffeld M, and Gund S. (2019). Ice Slurry History, current technologies and future developments. International Journal of Refrigeration. (99): 264-271.

Kauffeld M, Wang MJ, Golstein V, and Kasza KE. (2010). Ice Slurry Applications. International Journal of Refrigeration. 33(8): 1491-1505.

Liu X, Li Y, Zhuang K, Fu R, Lin S, and Li X. (2019). Performance Study and Efficiency Improvement of Ice Slurry Production by Scraped-Surface Method. Applied
Sciences. 9(74): 1-15.

Litaay C, Wisudo SH, Arfah H. 2020. Penanganan ikan cakalang oleh nelayan pole and line. Jurnal Pengolahan Hasil Perikanan Indonesia. 23(1): 112-121.

Metusalach, Kasmiati, Fahrul, Jaya I. 2014. Pengaruh cara penangkapan, fasilitas penanganan dan cara penanganan ikan terhadap kualitas ikan yang dihasilkan. Jurnal IPTEKS PSP. 1(1): 40-52.

Munandar A, Nurjanah, Nurilmala. 2009. Kemunduran mutu ikan nila (Oreochromis niloticus) pada penyimpanan suhu rendah dengan perlakuan cara kematian dan penyiangan. Buletin Teknologi Hasil Perikanan Indonesia. 12(2): 88-101.

Poernomo A, Poernomo SH. (2021). Susut Pasca-Panen Pangan dan Gizi Bidang Perikanan. Kertas Kerja Seri 2. Jejaring Pasca-Panen untuk Gizi Indonesia. ISSN 2775-4340:1-8.

Starling E, Diver G. 2005. The Australian Tuna Handling Manual: A Practical Guide for Industry. Queensland (AU): Seafood Service Australia. 